\title{
The Governance of Financial Regulation: Reform Lessons from the Recent Crisis
}

\author{
Ross Levine*
}

July 2010

\begin{abstract}
There was a systemic failure of financial regulation: Senior policymakers repeatedly enacted and implemented policies that destabilized the global financial system. They maintained these policies even as they learned of the consequences of their policies during the decade before the crisis. The crisis does not primarily reflect an absence of regulatory power, unclear lines of regulatory authority, capital account imbalances, or a lack of information by regulators. Rather, it represents the unwillingness of the policy apparatus to adapt to a dynamic, innovating financial system. I propose a new institution to improve the design, implementation, and modification of financial regulations.
\end{abstract}

Keywords: Financial Institutions, Regulation, Policy, Financial Crisis

JEL classification numbers: G20, G28, H1, E6

\footnotetext{
* James and Merryl Tisch Professor of Economics, Brown University, 64 Waterman Street, Providence RI, 02912, ross levine@brown.edu. I thank James Barth, John Boyd, Gerard Caprio, Peter Howitt, Randall Kroszner, Glenn Loury, Yona Rubinstein, Andrei Shleifer, Joe Stiglitz, David Weil, and Ivo Welch for helpful conversations and communications. Seminar participants at the Bank for International Settlements, the Boston and Chicago Federal Reserve Banks, the IMF, World Bank, George Washington University, and Brown University provided insightful comments. I bear full responsibility for the views expressed in the paper.
} 


\section{Introduction}

The first objective of this paper is to document that the collapse of the global financial system reflects a systemic failure of the governance of financial regulation - the system associated with designing, enacting, implementing, and reforming financial policies. Senior policymakers repeatedly designed, implemented - and most importantly maintained policies that destabilized the global financial system. They maintained these policies even as the regulatory authorities acquired information that their policies were increasing financial system fragility. Moreover, the authorities acquired this information during the decade before the crisis, when they had ample time to adjust their policies under relatively calm conditions. Yet, financial policymakers did not adjust, advertising weaknesses in the underlying governance of financial regulation.

In contrast to common narratives, my analyses, and those of Barth, Caprio, and Levine (2011), indicate that the crisis does not only reflect unsustainable global macroeconomic imbalances, the proliferation of toxic financial instruments, a lack of supervisory power, and unclear lines of regulatory authority. These factors played a role,

but only a partial role. Rather, bad policy choices created perverse incentives that encouraged financial institutions to take excessive risk and divert society's savings toward unproductive ends. Failures in the governance of financial regulation helped cause the global financial crisis.

In documenting deficiencies in the financial regulatory system, I stress the fatal inconsistency between a dynamic financial sector and a regulatory system that failed to adapt appropriately to financial innovation. Financial innovations, such as securitization, 
collateralized debt obligations, and credit default swaps, could have had primarily positive effects on the lives of most citizens. Yet, the inability, or unwillingness, of the governance apparatus overseeing financial regulation to adapt to changing conditions allowed these financial innovations to metastasize and ruin the financial system. A better functioning system for establishing financial policies could have captured the benefits, while avoiding the pain, associated with these new financial tools.

This conclusion - that systemic governance failures contributed to the crisis - has material implications for reforming financial regulation. There are several policy proposals to increase the power of financial regulatory agencies, reduce regulatory gaps, develop better crisis management tools, and consolidate the regulation of all systemically important institutions in the hands of a single entity. Yet, if technical glitches and regulatory gaps played only a partial role in fostering the crisis, then these proposed reforms represent only partial and thus incomplete steps in establishing a sound financial system. This is not an argument against the reforms that have been proposed and adopted. It is an argument for improving the governance of financial regulation. It is an argument for creating institutions that promote transparency, timely and informed debate, and hence the implementation of socially beneficial policies.

The second objective of the paper is to propose a new institution, which I label the "Sentinel," to act as the public's sentry over financial policies and thereby improve the governance of financial regulation. Its sole power would be to demand any information necessary for evaluating the state of financial regulation. Its sole responsibility would be to continuously assess and comment on financial policies, delivering a formal report to the legislative and executive branches of government annually. Critically, and uniquely, the 
Sentinel would be both politically independent and independent of financial markets. Senior members would be appointed for staggered terms to limit political influence. To shield it from market influences, senior staff would be prohibited from receiving compensation from the financial sector after completing public services for a timely period. The goal is to create an institution in which the personal motives, ambitions, and prestige of its employees are inextricably connected to accurately assessing the impact of financial regulations on the public.

The Sentinel would improve the entire apparatus for writing, enacting, adapting, and implementing financial regulations. As an extra group of informed, prying eyes, it would reduce the ability of regulators to obfuscate regulatory actions and would instead make regulators more accountable for the societal repercussions of their actions. As an additional group of experts reviewing and reporting on financial regulations, it would reduce the probability and costliness of regulatory mistakes and supervisory failures. As a prominent institution, the Sentinel's reports to legislators would help reduce the influence of special interests on the public's representatives. As an entity whose sole objective is to evaluate the state of financial regulation from the perspective of the public, it would help inform the public and thereby augment public influence over financial regulation.

Given the existing myriad of regulatory agencies, quasi-regulatory bodies, and other oversight entities, do we really need another regulatory institution? Yes. No other existing entity currently has the incentives, power, or capabilities to perform the role of a public sentry over the full constellation of financial sector policies.

First and foremost, unlike any existing institution, the Sentinel would be independent of both political and market influences. Incentives matter in regulation too. 
In capitals around the world, lobbyists shape legislation and the revolving door between industry and regulatory agencies spins rapidly. While there are good reasons for having highly-skilled individuals with private sector expertise help in regulating the financial sector, there are similarly good reasons for worrying about conflicts of interest and creating an independent, informed institution to improve the governance of financial regulation.

Second, no existing entity has the prominence, information, and expertise to challenge major regulatory agencies on financial policy matters. A monopoly on regulatory power and information is dangerous. Such a monopoly is particularly dangerous when it is housed in a central bank or other entity that is designed to be independent of the public and elected representatives. A monopoly on financial information, regulatory expertise, and regulatory power in the hands of publicly unaccountable officials breaks the democratic lines of influence running from the public to the design and execution of policies that determine the allocation of capital. The Sentinel would shine an illuminating, and potentially disinfecting, light on the financial system that would enhance the governance of financial regulation. Moreover, although the Sentinel would not set any policy, it would provide an objective, independent assessment of policy. This would have been enormously valuable during the decade-long series of policy gaffes that contributed to the current crisis.

While no panacea, the Sentinel would improve the regulatory apparatus. We face the complex, and consequential, challenge of creating a regulatory regime that adapts to incentivize financiers to provide the financial services necessary for economic growth. Incorporating the voice of a "Sentinel" would help. 


\section{Systemic Policy Failures}

\subsection{Introduction}

In this section, I argue that the collapse of the global financial system was partially caused by a systemic failure of financial regulation. To make this case, I focus on four policy failures. Though these examples focus on the United States, they have clear international connections. It should be remembered that while the bulk of toxic assets were made in the USA, financial institutions around the world readily purchased them, abetted by systemic regulatory failures in their home countries. Moreover, although I choose four policies, there are many examples that illustrate how financial regulators, with frequent help from their political overseers, did not act in the long interests of the public. Barth, Caprio, and Levine (2011) provide both more examples from the United States and from around the world in a book-length treatment of these themes. But, since the major objective of this paper is to recommend changes in the institutions associated with governing financial regulations, I keep this section brief.

\subsection{The Credit Rating Agencies}

As a first example of how regulatory actions - and inaction - helped trigger the crisis, consider credit rating agencies, which were central participants in the global financial crisis. To appreciate their role, consider the securitization of mortgages. Mortgage companies routinely provided loans to borrowers with little ability to repay those debts because (1) they earned fees for each loan and (2) they could sell those loans to investment banks and other financial institutions. Investment banks and other financial institutions 
gobbled-up those mortgages because (1) they earned fees for packaging the mortgages into new securities and (2) they could sell those new mortgage backed securities (MBSs) to other financial institutions, including banks, insurance companies, and pension funds around the world. These other financial institutions bought the MBSs because credit rating agencies said they were safe. By fueling the demand for MBS and related securities, credit rating agencies encouraged a broad array of financial institutions to make the poor investments that ultimately toppled the global financial system. Thus, an informed postmortem of the financial system requires a dissection of why financial institutions relied on the assessments of credit rating agencies.

How did credit rating agencies become so pivotal? Until the 1970s, credit rating agencies were insignificant institutions that sold their assessments of credit risk to subscribers. Now, it is virtually impossible for a firm to issue a security without first purchasing a rating.

In 1975, SEC created the Nationally Recognized Statistical Rating Organization (NRSRO) designation, which it granted to the largest credit rating agencies. The SEC then relied on the NRSRO's credit risk assessment in establishing capital requirements on SECregulated financial institutions.

The creation of -- and reliance on -- NRSROs by the SEC triggered a global cascade of regulatory decisions that increased the demand for their credit ratings. Bank regulators, insurance regulators, federal, state, and local agencies, foundations, endowments, and numerous entities around the world all started using NRSRO ratings to establish capital adequacy and portfolio guidelines. Furthermore, given the reliance by prominent 
regulatory agencies on NRSRO ratings, private endowments, foundations, and mutual funds also used their ratings in setting asset allocation guidelines for their investment managers.

Unsurprisingly, NRSROs shifted from selling their credit ratings to subscribers to selling their ratings to the issuers of securities. Since regulators, official agencies, and private institutions around the world relied on NRSRO ratings, virtually every issuer of securities was compelled to purchase an NRSRO rating if it wanted a large market for its securities.

There are well-known conflicts of interest associated with credit rating agencies selling their ratings to the issuers of securities. Issuers have an interest in paying rating agencies more for higher ratings since those ratings influence the demand for and hence the pricing of securities.

Nevertheless, credit rating agencies convinced regulators that reputational capital reduces the pernicious incentive to sell better ratings. If a rating agency does not provide sound, objective assessments of a security, the agency will experience damage to its reputation with consequential ramifications on its long-run profits. Purchasers of securities will reduce their reliance on this agency, which will reduce demand for all securities rated by the agency. As a result, issuers will reduce their demand for the services provide by that agency, reducing the agency's future profits. From this perspective, reputational capital is vital for the long-run profitability of credit rating agencies and will therefore contain any short-run conflicts of interest associated with "selling" a superior rating on any particular security.

Reputational capital will reduce conflicts of interest, however, only under particular conditions. First, the demand for securities must respond to poor rating agency 
performance, so that decision makers at rating agencies are punished for issuing bloated ratings on even a few securities. Second, decision makers at rating agencies must have a sufficiently long-run profit horizon, so that the long-run costs to the decision maker from harming the agencies reputation outweigh the short-run benefits from selling a bloated rating.

These conditions do not hold, however. First, regulations weaken the degree to which a decline in the reputation of a credit rating agency reduced demand for its services. Specifically, regulations induce the vast majority of the buyers of securities to use NRSRO rating in selecting assets. These regulations hold regardless of NRSRO performance, which moderates the degree to which poor ratings performance reduces the demand for NRSRO services. Such regulations mitigate the positive relation between rating agency performance and profitability. Second, financial innovation in the form of securitization dramatically changed the incentives of decision makers at credit rating agencies, inducing them to sell bloated ratings at the expense of a loss in the long-run reputation of the agency.

The explosive growth of securitized and structured financial products from the late1990s onward dramatically intensified the conflicts of interest problem. Securitization and structuring involves the packaging and rating of trillions of dollars worth of new financial instruments. Huge fees associated with processing these securities flowed to banks and NRSROs. Impediments to this securitization and structuring process, such as the issuance of low credit rating on the securities, would gum-up the system, reducing rating agency profits. In fact, the NRSROs started selling ancillary consulting services to facilitate the processing of securitized instruments, increasing NRSRO incentives to exaggerate ratings 
on structured products. Besides purchasing ratings from the NRSROs, the banks associated with creating structured financial products would first pay the rating agencies for guidance on how to package the securities to get high ratings and then pay the rating agencies to rate the resultant products.

By the early 2000s, it was well-known that the boom in securitization was encouraging credit rating agencies to inflate their ratings for huge profits. Moreover, regulators had seen the accounting debacle of 2001-2002, when corporations paid accounting firms both to structure and then to audit financial statements. So, when banks started paying the NRSROs both to structure and then to rate securities, this should have been a grim - and familiar - warning. The short-run profits associated with greasing the flow of structured products with optimistic ratings were mind bogglingly large and made the future losses from the inevitable loss of reputational capital irrelevant. For example, the operating margin at Moody's between 2000 and 2007 averaged 53 percent. This compares to operating margins of 36 and 30 percent at Microsoft and Google, or 17 percent at Exxon. It was good to be an NRSRO.

But, the global regulatory community did not adapt to these well-publicized developments. Regulatory agencies around the world protected NRSROs by continuing to rely on their ratings. While the global financial crisis does not have a single cause, the behavior of the credit rating agencies is a defining characteristic, and it is difficult to imagine the behavior of the credit rating agencies without the regulations that created and protected those agencies.

\subsection{Credit default swaps and bank capital}


Next, consider the role of complex derivative contracts, including credit default swaps. A credit default swap (CDS) is an insurance-like contract written on the performance of a security or bundle of securities. For example, purchaser A buys a CDS from issuer B on security C. If security C has a predefined "credit related event," such as missing an interest payment, receiving a credit downgrade, or filing for bankruptcy, then issuer B pays purchaser A. While having insurance-like qualities, CDSs are not formally insurance contracts. Neither the purchaser nor the issuer of the CDS needs to hold the underlying security, leading to the frequently used analogy that CDSs are like buying fire insurance on your neighbor's house. Moreover, since CDSs are not insurance contracts, they are not regulated as tightly as insurance products. CDSs are financial derivatives that are transacted in unregulated, over-the-counter (OTC) markets.

In principle, banks can use credit default swaps to reduce both their exposure to credit risk and the amount of capital held against potential losses. For example, if a bank purchases a CDS on a loan, this can reduce its credit risk: if the loan defaults, the counterparty to the CDS will compensate the bank for the loss. If the bank's regulator concludes that the counterparty to the CDS will actually pay the bank if the loan defaults, then the regulator typically allows the bank to reallocate capital to higher-expected return, higher-risk assets.

The Fed made a momentous decision in 1996: it permitted banks to use CDSs to reduce capital reserves (Tett, 2009, p. 49). Regulators treated securities guaranteed by a seller of CDSs as having the risk level of the seller - or more accurately, the counterparty of the CDS. For example, a bank purchasing full CDS protection from American International Group (AIG) on collateralized debt obligations (CDOs) linked to sub-prime 
loans would have those CDOs treated as AAA securities for capital regulatory purposes because AIG had an AAA rating from a Nationally Recognized Statistical Rating Organization, i.e., from a SEC-approved credit rating agency.

In light of this decision, banks used CDSs to reduce capital and invest in more lucrative, albeit more risky, assets. For example, a bank with a typical portfolio of $\$ 10$ billion of commercial loans could reduce its capital reserves against these assets from about $\$ 800$ million to under $\$ 200$ million by purchasing CDSs for a small fee (Tett, 2009 , $p$. 64).

The CDS market boomed following the Fed decision. By 2007, the largest U.S. commercial banks had purchased $\$ 7.9$ trillion in CDS protection, and, at a broader level, the overall CDS market reached a notional value of $\$ 62$ trillion in 2007 according to Barth et al (2009).

There were, however, serious problems associated with allowing banks to reduce their capital via CDSs. Given the active trading of CDSs, it was sometimes difficult to indentify the actual counterparty legally responsible for compensating a bank if an "insured" security failed. Furthermore, some bank counterparties developed massive exposures to CDS risk. For example, AIG had a notional exposure of about $\$ 500$ billion to CDSs (and related derivatives) in 2007, while having a capital base of about $\$ 100$ billion to cover all its traditional insurance activities as well as its financial derivatives business. The growing exposure of AIG and other issuers of CDSs should have - and did -- raise concerns about their ability to satisfy their obligations in times of economic stress.

The Fed was aware of the growing danger to the safety and soundness of the banking system from CDSs. For instance, Tett (2009, p. 157-163) recounts how Timothy 
Geithner, then President of the New York Federal Reserve Bank, became concerned in 2004 about the lack of information on CDSs and the growing counterparty risk facing banks. Barth et al (2009) demonstrates through the use of internal Fed documents that it knew by 2004 of the growing problems associated with subprime mortgage related assets, on which many CDSs were written. Indeed, the FBI publicly warned in 2004 of an epidemic of fraud in subprime lending. In terms of the sellers of CDSs, detailed accounts by Lewis (2009) and McDonald (2009) illustrate the Fed's awareness by 2006 of AIG's growing fragility and the corresponding exposure of commercial banks to CDS counterparty risk.

Yet, even more momentously than the original decision allowing banks to reduce their capital reserves through the use of CDSs, the Fed did not adjust its policies as it learned of the growing fragility of the banking system due to the mushrooming use of increasingly suspect CDSs.

The key question is why the Fed maintained its capital regulations. Bank purchases of CDSs boomed immediately after the 1996 regulatory decision allowing a reduction in bank capital from the purchase of CDSs. Why didn't the Fed respond by demanding greater transparency before granting capital relief and conducting its own assessment of the counterparty risks facing the systemically important banks under its supervision? Why didn't the Fed adjust in 2004 as it learned of the opaque nature of the CDS market and as the FBI warned of the fraudulent practices associated with the issuance of the sub-prime mortgages underlying many CDS securities, or in 2006 as information became available about the fragility of AIG, or in 2007 when hedge funds warned the Fed, the Treasury, and G8 delegates about the growing fragility of commercial banks (Tett, 2009, p. 160-3)? Why 
didn't the Fed prohibit banks from reducing regulatory capital via CDSs until the Fed had confidence in the financial viability of those selling CDSs to banks?

The Fed's decision to maintain its regulatory stance toward CDSs was neither a failure of information, nor a shortage of regulatory power. Based on a review of internal Fed documents, Barth et al (2009, p. 184) note, “... even if the top officials from these regulatory agencies did not appreciate or wish to act earlier on the information they had, their subordinates apparently fully understood and appreciated the growing magnitude of the problem." And, even in 2004, the Fed issued Interpretive Letter \#998 that reiterated its capital regulatory policy with respect to CDSs. To more comprehensively reform the financial regulatory system, we need to examine why these types of decisions were made and undertake institutional reforms to make these systemic mistakes less likely.

\subsection{Transparency vs. The FED, SEC, and Treasury}

As a third example, consider how powerful regulators and policymakers thwarted efforts to make the CDS market more transparent. The Fed (under Alan Greenspan), the Treasury (under Robert Rubin and then Larry Summers), and the SEC (under Arthur Levitt) squashed attempts by Brooksley Born of the Commodity Future Trading Commission (CFTC) to shed light on the multi-trillion dollar OTC derivatives market, which included credit default swaps, at the end of the 1990s.

Incidents of fraud, manipulation, and failure in the OTC derivatives market began as early as 1994, with the sensational bankruptcy of Orange County and court cases involving Gibson Greeting Cards and Procter and Gamble against Bankers Trust. Numerous problems, associated with bankers exploiting unsophisticated school districts and municipalities, 
plagued the market. Further, OTC derivates played a dominant role in the dramatic failure of Long-Term Capital Management (LTCM) in the summer of 1998. Indeed, no regulatory agency had any warning of LTCM's demise, or the potential systemic implications of its failure, because it traded primarily in this opaque market.

In light of these problems and the lack of information on the multi-hundred-trillion dollar OTC derivatives market, the CFTC issued a "concept release" report in 1998 calling for greater transparency of OTC derivatives. The CFTC sought greater information disclosure, improvements in record keeping, and controls on fraud. The CFTC did not call for draconian controls on the derivatives market; it called for more transparency.

The response by the Fed, Treasury, and SEC was swift: They stopped the CFTC. First, they obtained a six month moratorium on the CFTC's ability to implement the strategies outlined in its concept release. Second, the President's Working Group on Financial Markets, which consists of the Secretary of the Treasury, the Chairman of the Board of Governors of the Federal Reserve System, the Chairman of the SEC, and the Chairman of the CFTC, initiated a study of the OTC derivatives market. Finally, they helped convince Congress to pass the Commodity Futures Modernization Act of 2000, which exempted the OTC derivates market - and hence the CDS market - from government oversight.

Senior regulators and policymakers lobbied hard to keep CDSs and other derivatives in opaque markets. A comprehensive assessment of the causes of the crisis must evaluate why policymakers made choices like this. Indeed, Nick Timiraos and James R. Hagerty argue in The Wall Street Journal on February 9, 2010,

"Nearly a year and half after the outbreak of the global economic crisis, many of the problems that contributed to it haven't been tamed. The U.S. has no system in place to tackle a failure of its largest financial institutions. Derivatives contracts of the kind that crippled American International Group 
Inc. still trade in the shadows. And investors remain heavily reliant on the same credit-ratings firms that gave AAA ratings to lousy mortgage securities."

\subsection{Investment Bank Capital, Risk-Taking, and the SEC}

As a final example, consider the SECs oversight - or lack thereof - of the five major investment banks, all of which experienced major "transformations" in 2008. Only a few days after the SEC Chairman expressed confidence in the financial soundness of the investment banks, a failed Bear Stearns merged with the commercial bank JP Morgan Chase \& Co. Six months later, Lehman Brothers went bankrupt, and a few months later, at the brink of insolvency, Merrill Lynch merged with Bank of America. In the autumn of 2008, Goldman Sachs and Morgan Stanley were "pressured" into becoming bank holding companies by the Federal Reserve and arguably rescued from failure through an assortment of public programs. 
The SEC's fingerprints are indelibly imprinted on this debacle, as reflected in three interrelated SEC decisions. First, the SEC in 2004 essentially exempted the broker-dealers of the five largest investment banks from using the traditional method for computing capital in satisfying the net capital rule, which was a 1975 rule for computing minimum capital standards at broker-dealers. The investment banks were permitted to use their own mathematical models of asset and portfolio risk to compute appropriate capital levels. The investment banks responded by issuing more debt to purchase more risky securities without putting commensurately more of their own capital at risk. Leverage ratios soared from their 2004 levels, as the bank's models indicated that they had sufficient capital cushions.

In a second, coordinated 2004 policy change, the SEC enacted a rule that induced the five investment banks to become "consolidated supervised entities" (CSEs): The SEC would oversee the entire financial firm. Specifically, the SEC now had responsibility for supervising the holding company, broker-dealer affiliates, and all other affiliates on a consolidated basis. These other affiliates include other regulated entities, such as foreignregistered broker-dealers and banks, as well as unregulated entities such as derivatives dealers (Colby, 2007). The SEC was charged with evaluating the models employed by the broker-dealers in computing appropriate capital levels and assessing the overall stability of the consolidated investment bank. Given the size and complexity of these financial conglomerates, overseeing the CSEs was a systemically important and difficult responsibility.

Third, the SEC neutered its ability to conduct consolidated supervision of major investment banks. With the elimination of the net capital rule and the added complexity of 
consolidated supervision, the SEC's head of market regulation, Annette Nazareth, promised to hire high-skilled supervisors to assess the riskiness of investment banking activities. But, the SEC didn't. In fact, the SEC had only seven people to examine the parent companies of the investment banks, which controlled over $\$ 4$ trillion in assets. Under Christopher Cox, who became chairman in 2005 , the SEC eliminated the risk management office and failed to complete a single inspection of a major investment bank in the year and a half before the collapse of those banks (Labaton, 2008). Cox also weakened the Enforcement Division's freedom to impose fines on financial firms under its jurisdiction.

In easing the net capital rule, adopting a system of consolidated supervision, but failing to develop the capabilities to supervise large financial conglomerates, the SEC became willfully blind to excessive risk-taking. The SEC purposefully eliminated supervisory guardrails, while simultaneously arguing to the U.S. Congress in 2007 , and hence global financial markets, that it had a "successful consolidated supervision program." (See the SEC's Deputy Director's testimony before the U.S. House of Representatives Financial Services Committee, 4/25/2007, http://www.sec.gov/news/testimony/2007/ts042507rc.htm.) This forceful statement by the SEC provided an official stamp of approval of these major investment banks, weakening market monitoring of these enormously complex and highly leveraged conglomerates. These policy choices point inexorably toward the SEC as an accomplice in causing the global financial crisis. 


\subsection{Final Points on Systemic Policy Failures}

In example after example, the financial regulatory authorities:

(1) were aware of the problems associated with their policies,

(2) had ample power to fix the problems, and

(3) chose not to.

As noted by Senator Carl Levin, "The recent financial crisis was not a natural disaster; it was a manmade economic assault. It will happen again unless we change the rules."

\section{The Financial Regulatory Commission: The "Sentinel"}

\subsection{Preamble}

In light of the evidence presented above, I sketch a proposal for a Sentinel to improve regulatory governance: the system for selecting, interpreting, and implementing, and adapting regulations. One might accept the desirability of rethinking the governance of financial regulation and yet reject the specific Sentinel proposal. I simply offer the Sentinel as one potential strategy for improving the governance of financial regulation. Furthermore, in describing the Sentinel, I do not address a range of key questions, such as (i) which are the right regulations for achieving desirable outcomes, such as stability and growth and (ii) what are the right trade-offs among these potentially competing outcomes? Rather, the goal of the Sentinel is to improve the process through which these decisions are made. Finally, I sketch the Sentinel from the perspective of somebody most familiar with the institutional contours of the United States. While many of the general principles - such as transparency and checks and balances - translate to other political and cultural contexts, 
some elements will not. I emphasize key attributes of the Sentinel that are crucial to its proper functioning.

\subsection{The Sentinel}

The only power of the Sentinel would be to acquire any information that it deems necessary for evaluating the state of financial regulation over time, including the rules associated with the corporate governance of financial institutions. Any information collected by the Sentinel would be made publicly available, potentially with some delay. Transparency is necessary; thus, the law establishing the Sentinel must clearly and unambiguously assert that the Sentinel should be granted immediate and unencumbered access to any information it deems appropriate from any and all regulatory authorities and financial institutions. Sentinel demands for information must trump the desires of regulatory agencies for discretion, secrecy, and confidentiality. This "sunshine" regulatory approach has a long and promising history as discussed in McCraw's (1984) impressive book. This approach is also fully consistent with the notion of checks and balances incorporated into the political philosophies of several countries. In other words, the basic power of the Sentinel is quite conventional, not radical.

The only responsibility of the Sentinel would be to deliver an annual report to the legislative and executive branches of government assessing the current and long-run impact of financial regulatory and supervisory rules and practices on the public. The Sentinel would have no official power over the central bank, the regulatory agencies, or financial markets and institutions. To emphasize this point, the Sentinel would not affect the power and responsibilities of the central bank or financial regulatory agencies. But, the 
Sentinel would have broad responsibilities for assessing the impact of the overall constellation of regulatory and supervisory practices on the financial system, not just the impact of a single regulatory agency. The Sentinel would look across all segments of the financial system, from banks and securities markets, to derivatives and rating agencies, to insurance companies and executive compensation, etc, and produce a detailed evaluation of the functioning of the entire financial policy apparatus.

The major design challenges are to create a Sentinel that is (1) politically independent, (2) independent of financial markets, and (3) sufficiently staffed that it can deliver a message to a nation's policymakers, with sufficient prominence and prestige so that it is not ignored. These are essential ingredients. While elected official should ultimately set public policies, creating a Sentinel that is independent of narrow political and market influences would help in providing impartial, expert advice to politicians and the public. The goal is to create an institution in which the professional ambitions and personal goals of its staff align with its mission of boosting the degree to which financial regulations reflect the public interest. Given this goal and the Sentinel's responsibility of examining the complete financial system, it must have the staff and resources to deliver on these ambitious goals and responsibilities. While the objectives are the same, the precise organizational mechanisms for achieving such a Sentinel will necessarily differ across countries.

Here are a few design suggestions, using the United States as a point of reference. First, the most senior members of the Sentinel would be appointed by the President and confirmed by the Senate for staggered and appropriately long terms. As with the Board of Governors of the Federal Reserve System, the goal is to limit the short-term influence of 
politics on the evaluations of the Sentinel. Second, the senior members of the Sentinel would also be prohibited from receiving compensation from the financial services industry, even after completing their tenure at the Sentinel. Third, Sentinel salaries would have to be market based and the Sentinel would have to be large, including financial economists, lawyers, experts with supervisory experience, and - critically - senior professionals with private financial market experience. Since exactly those individuals with sufficient expertise to achieve the goals of the Sentinel would also have lucrative opportunities in the private sector, staffing the Sentinel with sufficiently talented, well-motivated individuals will require a different compensation schedule than currently contemplated in public sector jobs. While problematic, a more lucrative compensation plan is necessary for limiting conflicts of interest while attracting excellent people to the Sentinel. At the same time, the Sentinel would be a prominent entity. Those working for the Sentinel could achieve a wide-array of professional ambitions and attain considerable prestige and influence by accurately assessing financial regulations. The opportunity to improve financial sector policies and achieve these career aspirations would work to attract talented individuals to the Sentinel.

\subsection{Impact and desirability of the Sentinel}

The Sentinel would materially enhance the governance of financial regulation along several dimensions. At the most general level, creating an independent Sentinel with an informed and expert staff would enhance the analysis and review of financial policies, improve the design and implementation of those policies, and increase the probability that governments would select financial policies that promote the interests of the public at 
large, not only the special interests of a few. While the Sentinel would neither eliminate crises nor perfect financial system operations, it would improve the functioning of financial markets, lower the likelihood of systemic crises, and reduce the severity of future crises. It would accomplish these goals in several ways.

First, the Sentinel would have the power to demand information, the expertise to evaluate that information, and both the prominence and independence to make its judgments heard. It would be difficult for policymakers and the public to ignore the Sentinel's views. While regulators and others could refute the Sentinel's analyses and persuade policymakers to reject its recommendations, the Sentinel would provoke an informed debate.

By breaking the monopoly that regulatory authorities too frequently have over information and expertise, the Sentinel would enhance the analysis - and hence the design - of financial policies. Just as monopoly breeds inefficiencies in production, a monopoly on financial market and regulatory information by regulatory agencies breeds inefficiencies in the governance of financial policies. If the public and its representatives do not have the information and expertise to assess and challenge the decisions of the regulatory agencies, then this will hinder the effective design, implementation, and modification of financial sector policies. For example, while the Federal Reserve was aware of the destabilizing effects of its capital policies many years before the onset of the crisis, the public, Congress, and the Treasury would have found it difficult to obtain this information and discuss alternative policies with the Fed. A Sentinel would have reduced the probability that U.S. regulatory authorities would make the types of systematic mistakes over many years that helped trigger the 2008 global financial crisis. 
Critically, although the Sentinel would eliminate the monopoly by regulatory agencies on information and expertise, it would not limit the de jure power of these regulatory agencies. The Sentinel would force the regulators to defend their analyses, decisions, and actions, but it would not create another agency with regulatory power. The Sentinel would promote transparency and informed debate, but it would not diminish the role or responsibilities of existing regulatory agencies in promoting the safety and soundness of the financial system.

Second, in creating an informed, expert institution that is both independent of shortrun political forces and independent of the private profit motives of financial markets, the Sentinel would push the policy debate toward focusing on the general welfare of the public and away from the narrow interests of the politically powerful and financially wealthy.

This cannot be stressed enough. As emphasized by a vast literature, financial institutions pay virtually unlimited sums to shape financial policies, regulations, and supervisory practices to serve their private interests. As emphasized by an equally vast literature, narrow political constituencies work tirelessly on tilting the financial rules of the game so as to collect a greater share of the economy's resources.

Thus, it is vitally important to have an independent, expert, capable, and informed group to provide an objective assessment of financial policies. Such an institution does not exist in most countries, certainly not in the United States. While the Sentinel itself is imperfect, it is an improvement; it would help induce authorities to focus more on the public interest in selecting, implementing, and reforming financial policies.

Third, the Sentinel would examine the entire financial system. It would look beyond the narrow confines of any particular regulatory agency's purview and assess how the full 
constellation of financial policies fit together in shaping the incentives provided to private financial institutions. Again, no existing -- or proposed -- institution has both the independence and resources to perform this function effectively.

Fourth, the Sentinel would promote healthy financial innovation by continuously reassessing how regulatory and supervisory practices affect the incentives faced by the financial system. Since financial systems are dynamic, it is vital to relentlessly reevaluate the incentives shaping the behavior of financial market participants. As the latest crisis suggests, a regulatory system that worked well before structured financial products emerged did not work as well afterwards. By constantly assessing the impact of financial policies, the Sentinel would reduce the likelihood that financial policies become obsolete and thereby dangerously distort the incentives that shape financial market decisions.

Fifth, by (1) having responsibility for examining the entire financial system, (2) being politically independent and independent of financial markets, and (3) not having regulatory responsibilities, the Sentinel would be uniquely positioned to improve the performance of existing regulatory agencies. At the simplest level, knowing that the Sentinel is going to scrutinize its actions would increase the performance of regulatory agencies, reducing complacency. The mere existence of the Sentinel might have reduced the dubious actions and inactions of several regulatory bodies during the most recent crisis.

Furthermore, by having no official power over either the regulatory agencies or financial markets and institutions, the Sentinel would be less constrained in its assessments than an organization with direct supervisory and regulatory responsibilities. For example, if a regulator gives the $\mathrm{OK}$ on a particular practice, the regulator might later find it difficult to reverse or adjust its decision as new information becomes available. The 
regulator might have the very human fear of losing credibility with the regulated entity. While a regulator might avoid taking actions against a regulated financial institutions because such an ex post action implies an ex ante failure of regulation, the Sentinel would face fewer such conflicts. Thus, the Sentinel would make it more likely that bad policies are identified and changed. Similarly, while one regulatory agency (for example the Fed) might steer clear of criticizing another agency's actions (such as the SEC's) to avoid triggering cross-agency battles, the Sentinel would be less reticent. Indeed, it would have the responsibility of commenting on the performance and policies of all regulatory institutions, with positive ramifications on the governance of financial regulation.

\section{Conclusions}

The financial crisis was not simply the result of too little regulatory power, unclear lines of regulatory authority, or the unpredictable consequence of massive, unsustainable capital flows in conjunction with toxic financial innovations. All of these were contributing factors. But, they are incomplete explanations of the collapse of the global financial system. A systemic failure of financial regulation contributed to the crisis. The major financial regulatory agencies repeatedly designed, implemented, and maintained policies that increased the fragility of the financial system and the inefficient allocation of capital. The financial policy apparatus maintained these policies even as they learned that their policies were distorting the flow of credit toward questionable ends. They had plenty of time to assess the impact of their policies and adapt, but they frequently failed to change their policies. Thus, the institutions responsible for maintaining the safety and soundness of the global financial system made systematic mistakes. Thus, a comprehensively effective 
financial reform package must address the systemic failure of the governance of financial regulation - the system associated with evaluating, enacting, and implementing financial policies.

The Sentinel is a suggestion for addressing this fundamental cause of the global financial crisis. Unlike existing institutions, the Sentinel would be independent of both political and market influence. Supervisory and regulatory officials in many countries move readily from politically-connected jobs, to lucrative jobs in the private sector, to senior positions in official financial supervisory agencies. While the vast majority of regulators surely act in the best interests of the public, it is nevertheless valuable to have an informed, expertly-staffed institution - without potential conflicts of interest - assessing the performance of official agencies and the efficacy of financial policies. While existing regulatory agencies frequently have internal auditing departments, the Sentinel would play a much different role. These auditing departments assess whether the particular regulatory agency adhered to particular rules. Instead, the Sentinel would conduct an independent evaluation of the impact of the full array of financial regulations and supervisory practices on the economy.

Unlike existing institutions, the Sentinel would have the prominence, information, and expertise to question existing regulatory agencies. It is anti-democratic, and economically dangerous, for a group of unelected regulatory officials to have a monopoly on the information and expertise necessary for making financial regulatory decisions. This gives too much power over the rules governing the allocation of capital to unelected, and potentially unaccountable, officials. The Sentinel would shine a cleaning light on the processes associated with making financial policy decisions, enhancing financial regulation. 
The Sentinel would provide an independent, expert assessment of financial sector policies that would inform the debate on these highly complex policy considerations. The absence of such an institution was clearly evident in the design, implementation, and evolution of financial policies during the last decade.

Although not impervious to mistakes and corruption itself, the Sentinel would enhance the governance of financial regulation. It would increase the probability of creating a regulatory system that adapts to a dynamic, innovating economy and incentivizes financiers to provide the financial services necessary for sustaining economic growth. 


\section{References}

Barth, James R., Gerard Caprio, Jr., and Ross Levine. 2006. Rethinking Bank Regulation: Till Angels Govern. New York: Cambridge University Press.

Barth, James R., Gerard Caprio, Jr., and Ross Levine. 2011. Guardians of Finance: How to Make them Work for Us. Cambridge, MA: MIT Press, forthcoming.

Barth, James R., Tong Li, Wenling Lu, Tiphon Phumiwasana, Glenn Yago. 2009. The Rise and Fall of the U.S. Mortgage and Credit Markets. Hoboken, NJ: Wiley \& Sons, Inc.

Cecchetti, Stephen G. 2009. Crisis and Responses: The Federal Reserve in the Early Stages of the Financial Crisis. Journal of Economic Perspectives 23, 51-75.

Colby, Robert. 2007. Testimony Concerning the Consolidated Supervision of U.S. Securities Firms and Affiliated Industrial Loan Corporations. The U.S. House of Representatives Financial Services Committee, April 25, 2007.

Labaton, Stephen. 2008. Agency's '04 Rule Let Banks Pile Up New Debt. New York Times, October 3, 2008.

Levine, Ross. 2010a. The Sentinel: Improving the Governance of Financial Policies. In The International Financial Crisis: Have the Rules of Finance Changed? Eds: Asli Demirguc-Kunt, Douglas D. Evanoff and George G. Kaufman, World Scientific Publishing Co. Pte. Ltd, New Jersey.

Levine, Ross. 2010b. An Autopsy of the U.S. Financial System: Accident, Suicide, or Negligent Homicide? Journal of Financial Economic Policy forthcoming.

Lewis, Michael. 2009. The Man Who Crashed the World. Vanity Fair, August.

Lowenstein, Roger. 2008. Triple-A Failure. New York Times, April 27.

McDonald, Lawrence G. and Patrick Robinson. 2009. A Colossal Failure of Common Sense: The Inside Story of the Collapse of Lehman Brothers. New York, NY: Crown Publishing Company.

Tett, Gillian. 2009. Fool's Gold. New York, NY: Free Press. 